\title{
Larval abundance, recruitment and early mortality in Paracentrotus lividus (Echinoidea). Interannual variability and plankton-benthos coupling
}

\author{
Salvador López ${ }^{1}$, Xavier Turon ${ }^{1, *}$, Elena Montero ${ }^{1}$, Cruz Palacín ${ }^{1}$, \\ Carlos M. Duarte ${ }^{2}$, Isabel Tarjuelo ${ }^{1}$
}

${ }^{1}$ Dept of Animal Biology (Invertebrates), Faculty of Biology, Univ. of Barcelona, 645, Diagonal Ave, E-08028 Barcelona, Spain ${ }^{2}$ Centre d'Estudis Avançats (CSIC), Camí de Sta. Bàrbara, s/n, E-17300 Blanes (Girona), Spain

\begin{abstract}
The temporal patterns of larval abundance, recruitment and early mortality in the sea urchin Paracentrotus lividus (Lamarck) in the northwestern Mediterranean were studied by combining planktonic and benthic surveys. The abundance of planktonic stages was monitored by weekly plankton hauls from 1992 to 1996 . The presence of juveniles was studied by collecting epibenthic samples at monthly intervals from 1992 to 1995. The size distribution of the same population was studied in 1993. A main recruitment episode in late spring-summer occurred every year, although small recruitment events had been observed in autumn and winter. Interannual variability in larval abundance and recruitment was high, both being most intense in 1992, when up to 33.47 larvae $\mathrm{m}^{-3}$ were recorded in plankton samples, and up to 23000 recruits (sea urchins $<2 \mathrm{~mm}$ ) $\mathrm{m}^{-2}$ were found in the benthic samples. We estimated that only about $12.7 \%$ of larvae (from the 8 -armed stage onwards) survived the planktonic life, and that 0.5 to $0.7 \%$ of the settlers survived until they reached a diameter of $2 \mathrm{~mm}$, while $0.040 \%$ of settlers survived the first year of benthic life and only $0.028 \%$ of settlers may attain reproductive size. The main bottlenecks in the dynamics of this species occurred, therefore, during the planktonic phase and the first year of benthic existence, particularly during the early post-settlement phase. The benthic samples provided a more robust depiction of events than planktonic data, which featured a higher variability. There was a significant relationship between the interannual variation in the late winter phytoplankton bloom and the spring peak of larvae of this species, indicating that changes in larval abundance are coherent with changes in planktonic primary production. There was also an exponential negative relationship between the abundance of larvae and abundance of recruits relative to larvae over the years studied, indicating density-dependent mortality rates in the planktonic and early benthic stages. Successful cohorts of this species can be traced to years with high larval abundance, which in turn are related to episodes of high planktonic primary production.
\end{abstract}

KEY WORDS: Plankton-benthos coupling - Larval abundance - Recruitment - Early mortality Echinoidea

\section{INTRODUCTION}

The recruitment of benthic invertebrates involves 3 main steps: larval supply, settlement, and survival of juveniles (Cameron \& Schroeter 1980, Harrold et al. 1991), whose study poses distinct methodological problems. Larval distribution in the plankton is patchy and variable, both spatially and temporally (e.g.

\footnotetext{
- Addressee for correspondence.
}

E-mail: xaviert@porthos.bio.ub.es
Pedrotti \& Fenaux 1992, Martin et al. 1997). The assessment of settlement is problematic because of the small size of juveniles and because rapid mortality before observation leads to underestimation (Harrold et al. 1991, Pearse \& Cameron 1991, Ebert et al. 1994), rendering early mortality difficult to evaluate (Gosselin \& Qian 1997, Hunt \& Scheibling 1997). Yet, studies encompassing all 3 processes determining recruitment are necessary to identify bottlenecks (Hunt \& Scheibling 1997). Moreover, these studies must be necessarily interannual, because inferences on early population 
dynamics based on a limited observational period may be misleading. In fact, echinoids are known to feature high interannual variation in recruitment, with exceptionally strong episodes intermingled with years of poor recruitment (Ebert 1983, Pearse \& Hines 1987), although the causes of this variation in cohort strength are poorly known.

We report here the interannual patterns of recruitment and colonisation of Paracentrotus lividus (Lamarck), the most abundant regular echinoid species in the shallow littoral of the northwestern Mediterranean (Turon et al. 1995b). P. lividus has an Atlanto-Mediterranean distribution, where it grows down to $80 \mathrm{~m}$ in depth, although it is most abundant within the top $20 \mathrm{~m}$ (Kempf 1962, Fenaux 1968). This species is one of the main herbivores in the sublittoral, able to regulate seaweed biomass (Nédelec \& Verlaque 1984, Verlaque 1984, Palacín et al. 1998), and it is harvested for consumption of its roe.

In spite of the ecological and commercial importance of Paracentrotus lividus, some aspects of its population dynamics are still poorly known (Lozano et al. 1995, Turon et al. 1995a, Sala \& Zabala 1996), particularly so for its reproductive cycle, spawning and recruitment. Conflicting reports describe a recruitment episode in spring-summer (e.g. Azzolina 1988, Byrne 1990, Lozano et al. 1995, Spirlet et al. 1998) or 2 distinct periods of recruitment (spring and autumn; cf. Fenaux 1968, Crapp \& Willis 1975, Verlaque 1984, Pedrotti 1993). Contrasting reproductive periodicities have been described for different populations in the same geographic area (Guettaf 1997). This disparity is partly due to the use of different methods to study the repro-

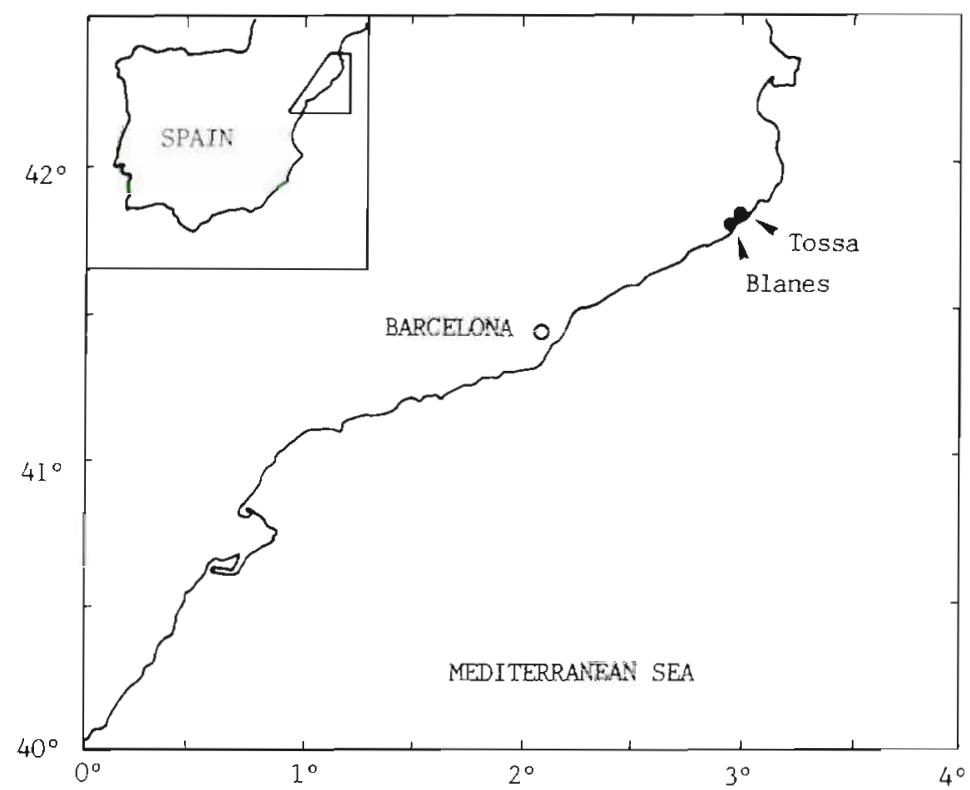

Fig. 1. Map of the study area showing sampling sites ductive periodicities of this species (e.g. time course of gonadosomatic indices, cohort studies, gonad histology, plankton samples). There is also some confusion between decreases in gonad weight and spawning episodes, or between yearly number or spawning events and number of gametogenic cycles.

The goals of this paper are (1) to provide a multipleapproach determination of the timing and intensity of recruitment, as well as the early mortality, in this species, (2) to ascertain interannual variation in larval abundance and recruitment, and to assess the factors associated with this variation, and (3) to compare different techniques used to estimate recruitment (plankton samples, benthic samples, cohort analyses).

\section{MATERIAL AND METHODS}

The study was performed on the northeast coast of Spain (northwestern Mediterranean). Benthic samples were collected at Tossa de Mar $\left(41^{\circ} 43.2^{\prime} \mathrm{N}, 2^{\circ} 56.4^{\prime} \mathrm{E}\right)$, while plankton samples were collected in the neighbouring Bay of Blanes (Fig. 1). The main littoral current in the area is parallel to the shore and directed southwards.

Plankton samples. The abundance of larvae in the plankton was estimated in samples at approximately weekly intervals between 1992 and 1996. The samples were collected by oblique hauls from 10 to $0.5 \mathrm{~m}$ in depth made with a Juday-Bogorov net in a littoral zone in which the bottom was approximately at $15 \mathrm{~m}$ depth. The net had a pore size of $250 \mu \mathrm{m}$ and a circular aperture $0.5 \mathrm{~m}$ in diameter. The net was trawled for $2 \mathrm{~min}$ at low speed ( 3 to 4 knots), and the volume of water filtered (usually about $100 \mathrm{~m}^{3}$ per haul) was recorded by a calibrated flow-meter. The plankton samples were fixed in formalin, and whole samples or an aliquot of them (depending on the abundance of zooplankton) were examined under a stereomicroscope. The numbers of plutei, plutei with rudiment, and postlarvae (sensu Fenaux \& Pedrotti 1988) of Paracentrotus lividus were recorded and transformed to abundance in ind $\mathrm{m}^{-3}$. We also measured surface water temperature, and chlorophyll a and gross primary production were measured as well (Agustí unpubl. data), using a fluorimeter and microwinkler determination of oxygen evolution, respectively (cf. Mura et al. 1996 and Satta et al. 1996, respectively, for details on the methods).

Identification of echinoid larvae in the plankton samples followed Pressoir (1959), Fenaux (1969) and Mortensen (1977). The 
echinoplutei of Paracentrotus lividus are easily discernible because the posterior end of the body is elongated and supported by club-shaped body rods. As development proceeds, however, the posterior part of the body rods degenerates and the body end widens. In intermediate stages, remnants of the distal extremes of the body rods can still be seen at the posterior tip of the body. At the stage of plutei with rudiment, pedicellaria (normally 1 pair) develop on the right hand side of the body in many individuals, and then become positioned on the aboral side of the postlarvae.

Benthic samples. For the benthic study, we selected a vertical wall facing NW between 0 and $10 \mathrm{~m}$ in depth. This wall was wide (about $40 \mathrm{~m}$ ) and physically uniform, with few crevices or places inaccessible for sampling. The wall was occupied by a photophilic assemblage of soft seaweeds dominated by Corallina elongata Ellis \& Solander (in the first meters) and Halopteris scoparia (L.) Sauvageau, with a variety of other algal species, such as Dictyota dichotoma var. intricata (Agardh) Greville, Falckenbergia rufolanosa (Harvey) Schmidt and Padina pavonica (L.) (Thivy). Under these soft algae there was a layer of crustose coralline algae (Lithophyllum incrustans Philippi in the shallower zone and Mesophyllum lichenoides Ellis [Lémoine] at depths of more than $4 \mathrm{~m}$ ). Some invertebrates, especially sponges such as Ircinia spp. and Crambe crambe (Schmidt), were also present. This place is believed to be a good habitat for sea urchin settlement and growth, as it combines abundant food sources (soft algae) with the hiding places (in small interstices and crevices of the crustose algae) favoured by young sea urchins (Kempf 1962, Verlaque 1984, Sala \& Zabala 1996, authors' pers. obs.).

Samples were obtained by delimiting $20 \times 20 \mathrm{~cm}$ squares using an aluminium frame. The squares were placed haphazardly, but within selected depth levels (see below). All the organisms (including the basal layer of crustose algae) present within the squares were scraped off with the help of a hammer and chisel and placed in plastic bags underwater We were confident that, with this method, losses of sea urchins during sampling would be minimal. Sampled areas remain bare for some time after sampling, but due to the size of the wall, repeated sampling was possible with a negligible effect on the community.

All samples were fixed in formalin and examined under the stereomicroscope. The number of sea urchin recruits $(<2 \mathrm{~mm}$ in diameter) was recorded and their size was measured with a calibrated ocular lens.

From June 1992 to July 1993, 3 samples were taken on this wall every $2 \mathrm{wk}$ at 3,6 , and $9 \mathrm{~m}$ depth $(1 \mathrm{sam}$ ple per depth level\}. In October and December 1993 , 3 further samples (1 at each depth) were taken per month. At this time, the first part of the study ended, and the preliminary results were reported as part of a study on the reproductive cycles of this species (Lozano et al. 1995). We then continued the monitoring by taking 3 replicate samples per month at each depth, totalling 9 samples per month. This second part of the study lasted from June 1994 to December 1995. The data set, therefore, extends over 4 recruitment seasons, corresponding to the years 1992 to 1995. The depth distributions of recruits and of the established sea urchins (i.e. specimens larger than $5 \mathrm{~mm}$ in diameter) were compared on the basis of a data set of sea urchin abundance on the same wall and at the same 3 depth levels during 1992-93 (Turon et al. 1995a).

Calculations of mortality were based on data from the 1992 and 1995 recruitment events, which were the most intense recorded in our benthic samples and provided the most precise estimates. Our analyses benefited from the time series of size-frequency distributions performed during 1993 on the same wall as the recruitment study (Turon et al. 1995a), which allowed us to trace the time course of the 1992 cohort in the 1993 samples. Cohorts were identified in these histograms through modal analysis using the Battacharya method (Battacharya 1967) with the ELEFAN program (ICLARM software; Pauly \& David 1981), and skeletal ring counts were used to age the size-classes found (Turon et al. 1995a).

\section{RESULTS}

The highest larval abundances were observed in spring 1992 (Fig. 2). The highest monthly mean of plutei abundance was found in June 1992 (6.80 plutei $\left.\mathrm{m}^{-3}\right)$, when the highest abundance recorded in any one sample (33.47 plutei $\mathrm{m}^{-3}$ ) was observed. The very high variance of plutei densities found during June 1992 resulted from the fact that some samples were almost devoid of larvae, while most of the larvae observed were concentrated in one sample. In contrast, larval abundance was very low between 1993 and 1994, while distinct spring peaks, although much lower than that in 1992, were observed again in 1995 and 1996 (Fig. 2). Small numbers of plutei without rudiment were occasionally observed in autumn or winter (October 1993, January 1994, January 1995, January and February 1996), indicating small spawning events during these periods. Most of the plutei observed corresponded to late stages (8-armed plutei or plutei with rudiment); only in May-June 1992 was an appreciable number of 4-and 6-armed plutei observed. Closer examination of the spawning event of spring 1992 reveals a temporal overlap between forms: 4 - and 6-armed plutei were found between 28 May and 1 June, when 8-armed plutei were already the most abundant form. Plutei 


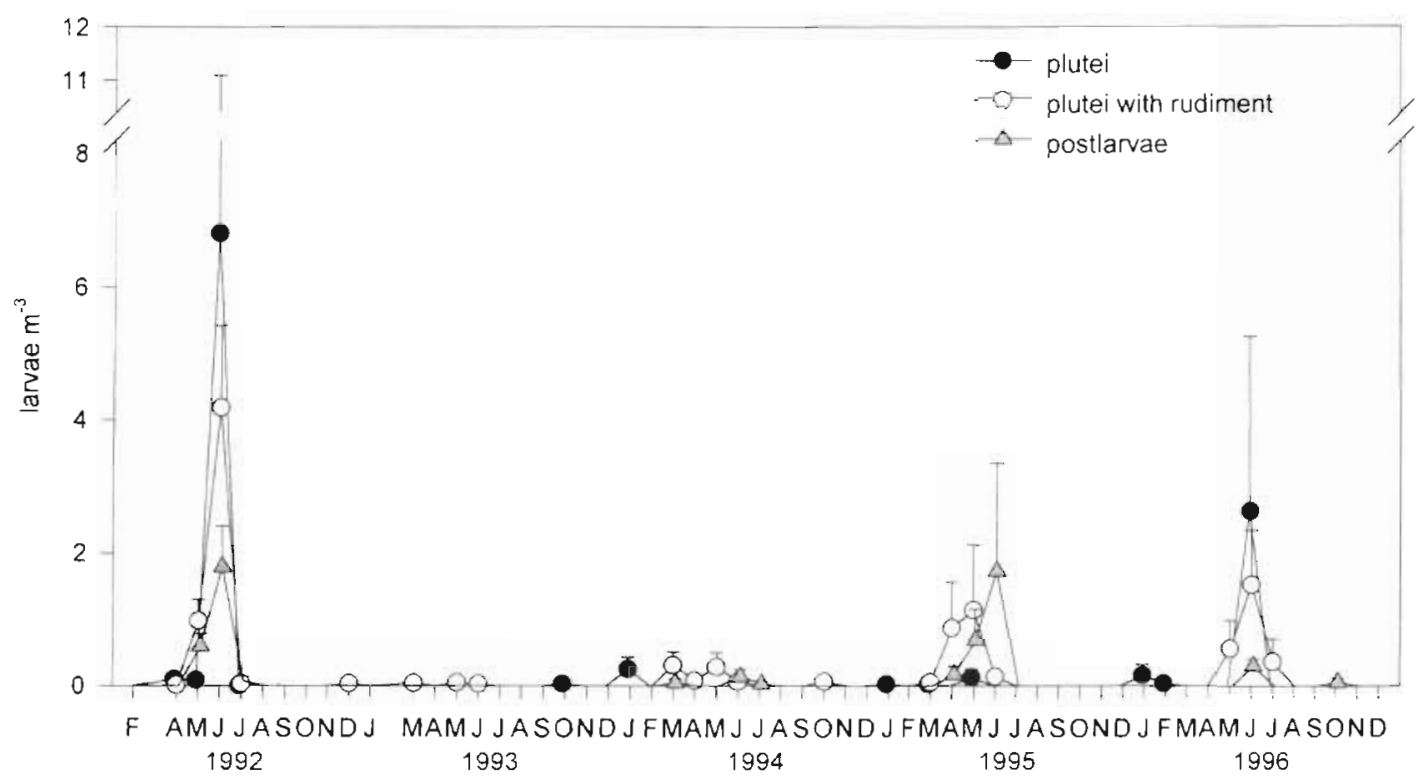

Fig. 2. Paracentrotus Iividus. Abundance (monthly means) of the different planktonic stages in the plankton samples during the study period. Bars are standard errors

with rudiment and postlarvae dominated in later samples, from 4 June onwards (Fig. 3).

The progressive reduction in the peak abundance of plutei, plutei with rudiment, and postlarvae observed in 1992, the year for which we recorded the highest number of larvae, allowed estimation of mortality rates of the planktonic phases. Fitting the equation $N_{t}=$ $N_{0} \mathrm{e}^{-Z t}$, where $N_{t}$ and $N_{0}$ are abundance at time $t$ and time 0 , respectively, and $Z$ is instantaneous mortality rate, yielded an estimated $Z$ value of $0.34 \mathrm{~d}^{-1}$ between the stages of plutei and of plutei with rudiment, and of $0.10 \mathrm{~d}^{-1}$ between the plutei and postlarvae stages. The corresponding finite survival rates were $25.6 \%$ be-

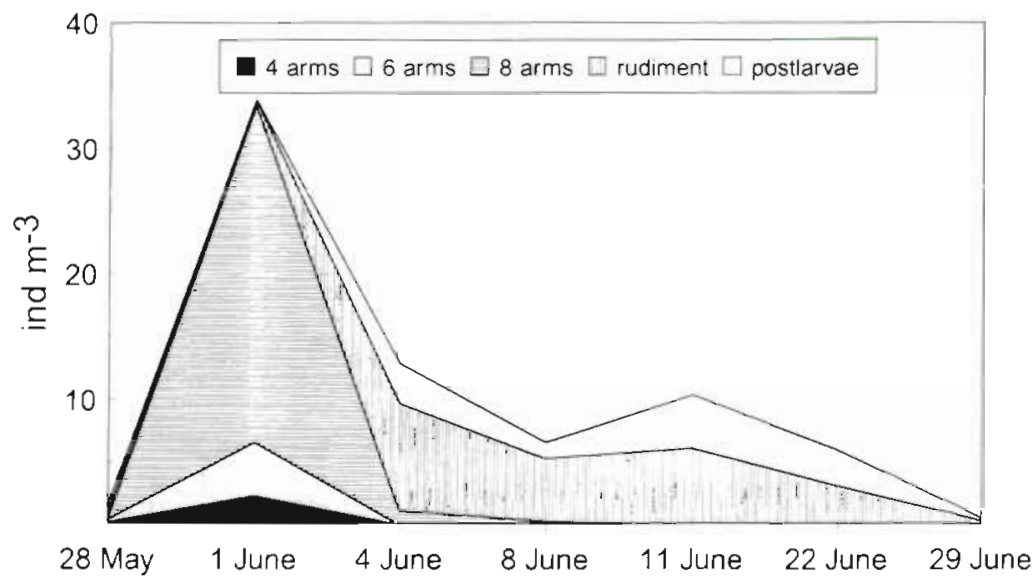

Fig. 3. Paracentrotus lividus. Abundance of the diverse larval stages $(4-, 6-$, and 8-armed plutei, plutei with rudiment, and postlarvae) during the peak of larvae observed in May-June 1992 tween plutei and plutei with rudiment and $12.7 \%$ between plutei and postlarvae. As most of the plutei recorded were already advanced (8-arms stage), these values underestimate to some unknown degree the total mortality during the planktonic life. Migration phenomena, as well as changes in the larval stocks due to alongshore currents, can also confound our mortality estimates (see 'Discussion').

Phytoplankton biomass also changed considerably both within and between years, showing little consistent seasonality, except for the occurrence of a late winter (late February to March) bloom every year (Fig. 4), which represents the main annual event (cf. Mura et al. 1996). There were other blooms occurring during the year although these did not occur consistently over the entire period (e.g. July 1992, October 1994i Fig. 4). The magnitude of the late winter phytoplankton. bloom differed greatly among years, with that observed in 1992 being far greater than those in subsequent years, and moderately high blooms were observed again in 1995 and 1996 (Fig. 4). These interannual differences mirror those observed for the abundance of planktonic stages of Paracentrotus lividus (Fig, 2), suggesting that changes in these blooms influence the size of the larval pool. There is a clear relationship $(r=0.97, p<0.01)$ between gross primary production of the late 


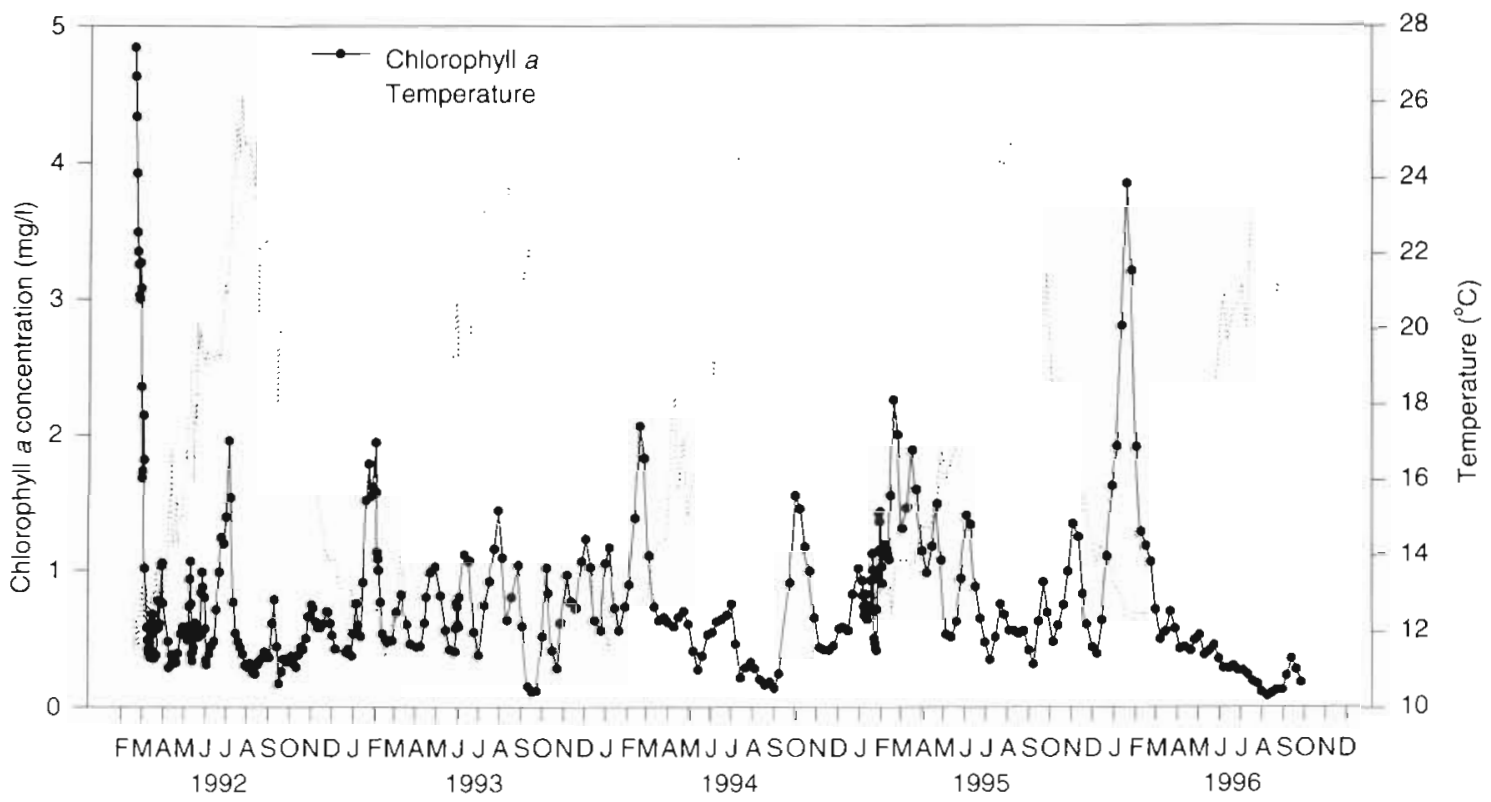

Fig. 4. Paracentrotus lividus. Chlorophyll a concentration in the plankton samples (smoothed by a moving average 3 points wide) and water temperature over the study period

winter bloom and the maximum monthly larval abundance in spring over the years studied (Fig. 5).

The average abundance of benthic recruits (juveniles less than $2 \mathrm{~mm}$ in diameter) differed greatly during the study period (Fig. 6). The high larval abundance observed in 1992 was associated with the greatest recruitment to the benthos in the summer of that year. The number of recruits was higher in 1992 and 1995 than in the intervening years, and was particularly low in 1993. The highest abundance of recruits was observed in August 1992, averaging 7050 recruits $\mathrm{m}^{-2}$ (monthly mean), while the maximum abundance obtained in any one sample was 22925 ind. $\mathrm{m}^{-2}$.

A main recruitment event in late spring-summer was a consistent feature of the 4 years studied (Fig, 6). In fact, this recruitment episode occurred progressively

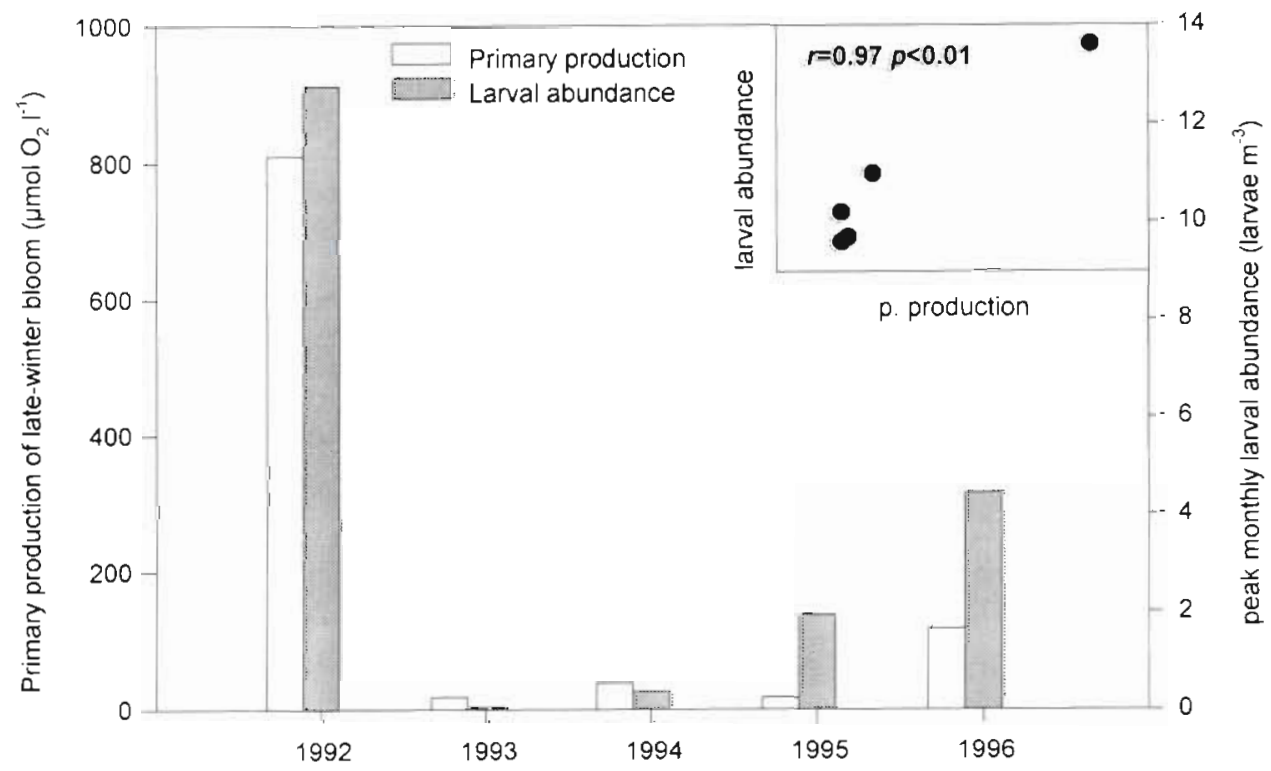

Fig. 5. Paracentrotus lividus. Primary production of the late-winter planktonic bloom (integrated over the duration of this bloom for each year) and maximum monthly abundance of larvae (all planktonic stages pooled) in the plankton from 1992 to 1996 . Inset: relationship between the variables 


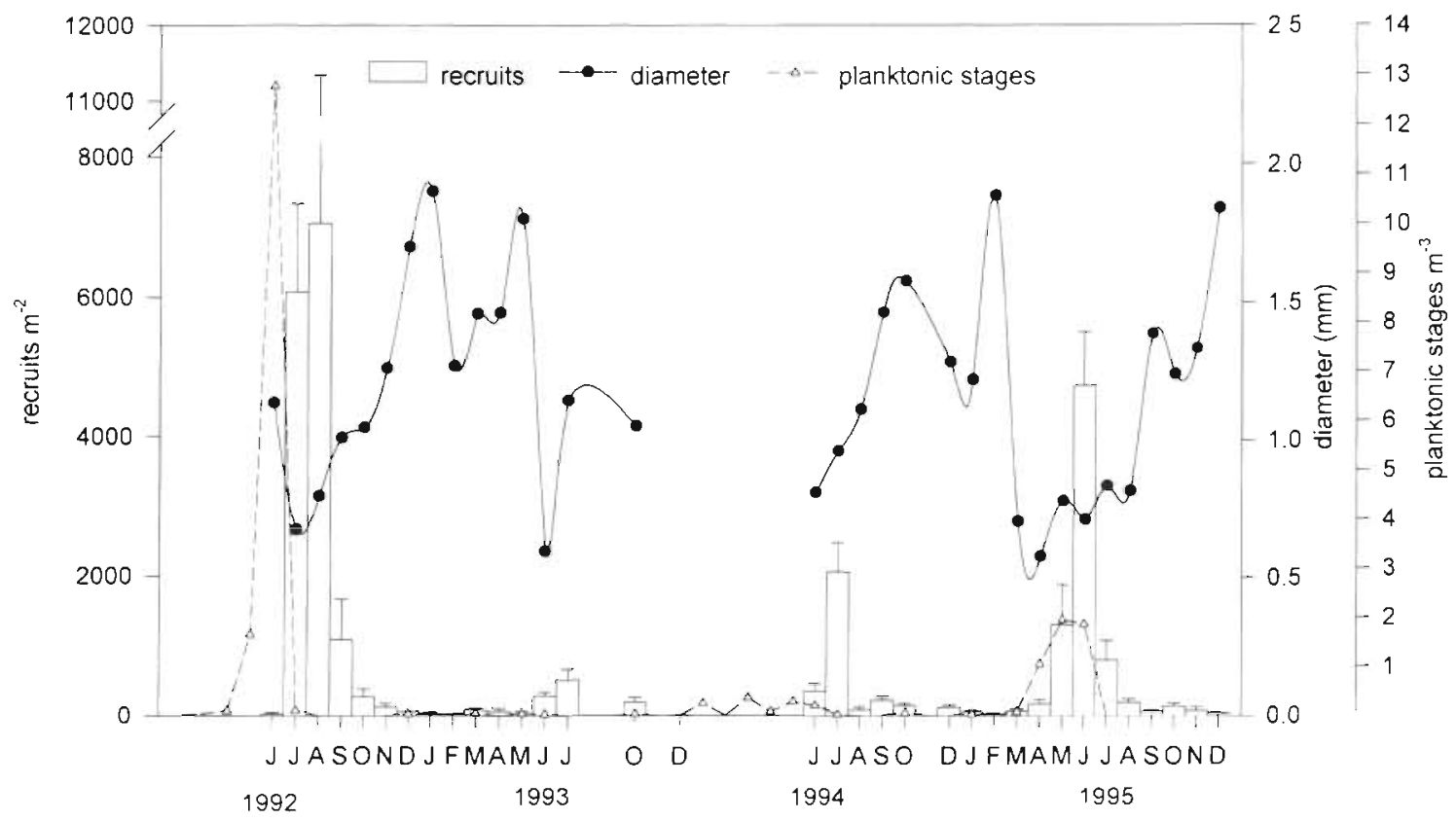

Fig. 6. Paracentrotus lividus. Abundance and mean diameter of recruits (monthly means at all depths) over the study period. Bars are standard errors. The temporal sequence of monthly mean abundance of planktonic stages (plutei, plutei with rudiment and postlarvae pooled) during the same period is added for comparison

earlier during the study (July-August in 1992, JuneJuly in 1993 and 1994, and May-June in 1995). Water temperature measurements taken at all sampling dates showed that there was also an advancement in the spring temperature rise during these years (e.g. a temperature of $20^{\circ} \mathrm{C}$ was reached by the end of July in

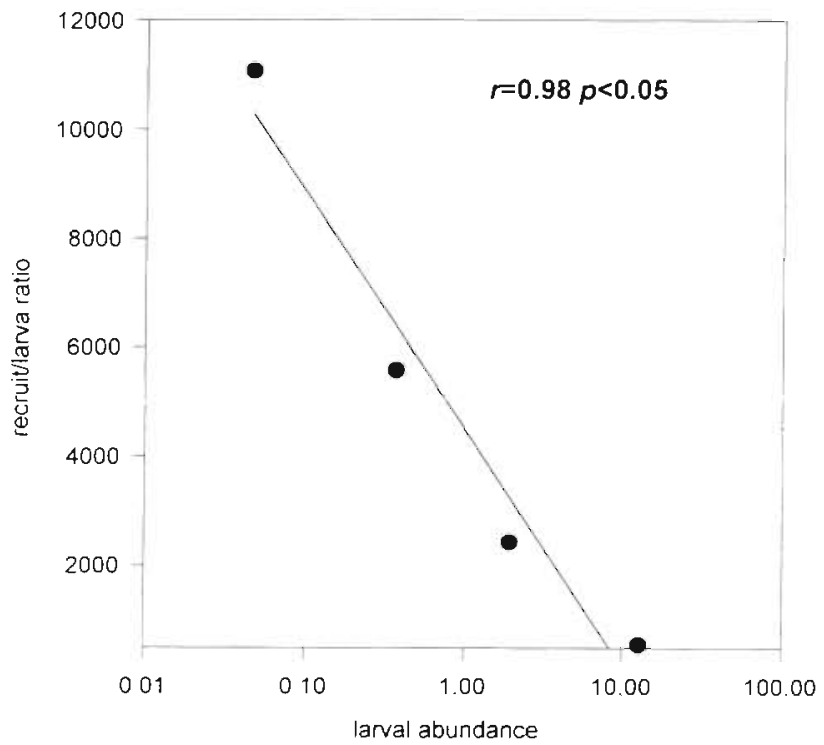

Fig. 7. Paracentrotus lividus. Relationship between maximum monthly larval abundance and maximum monthly recruitment intensity relative to larval abundance during the years surveyed
1992, and by the end of June in 1995). Scattered recruits were present in autumn and winter during the 4 years, although there was no clear peak of recruitment during these seasons comparable to those observed in spring-summer (Fig. 6). The presence of planktonic stages preceded the arrival of recruits to the bottom. This temporal sequence was clearest (Fig 6) in the years (1992 and 1995) with high recruitment, which were also those with high larval release and planktonic primary production. The maximum abundance of larvae in the plankton and peak recruitment intensity over the 4 years surveyed were positively associated, but the latter did not increase linearly with larval abundance, rather, there is a negative exponential relationship ( $\mathrm{r}=$ $0.98, p<0.05$ ) between peak larval abundance and amount of recruits relative to larvae (Fig. 7), indicating that planktonic mortality (or postsettlement mortality prior to observation) may be density-dependent.

The recruitment episodes were clearly reflected in the size structure of the juveniles (Fig. 8). Newly settled sea urchins had sizes $\leq 0.6 \mathrm{~mm}$. The few juveniles observed in autumn-winter appeared to be mostly the result of the growth of the spring-summer recruits, although arrival of a small number of new recruits of the smallest size-classes was observed in October and December 1994 and October 1995 (Fig 8). The sizefrequency histograms corresponding to 1992-93 were already presented in Lozano et al. (1995), and essentially the same results were found. Although the mean size of the recruits can fluctuate due to overlap of 

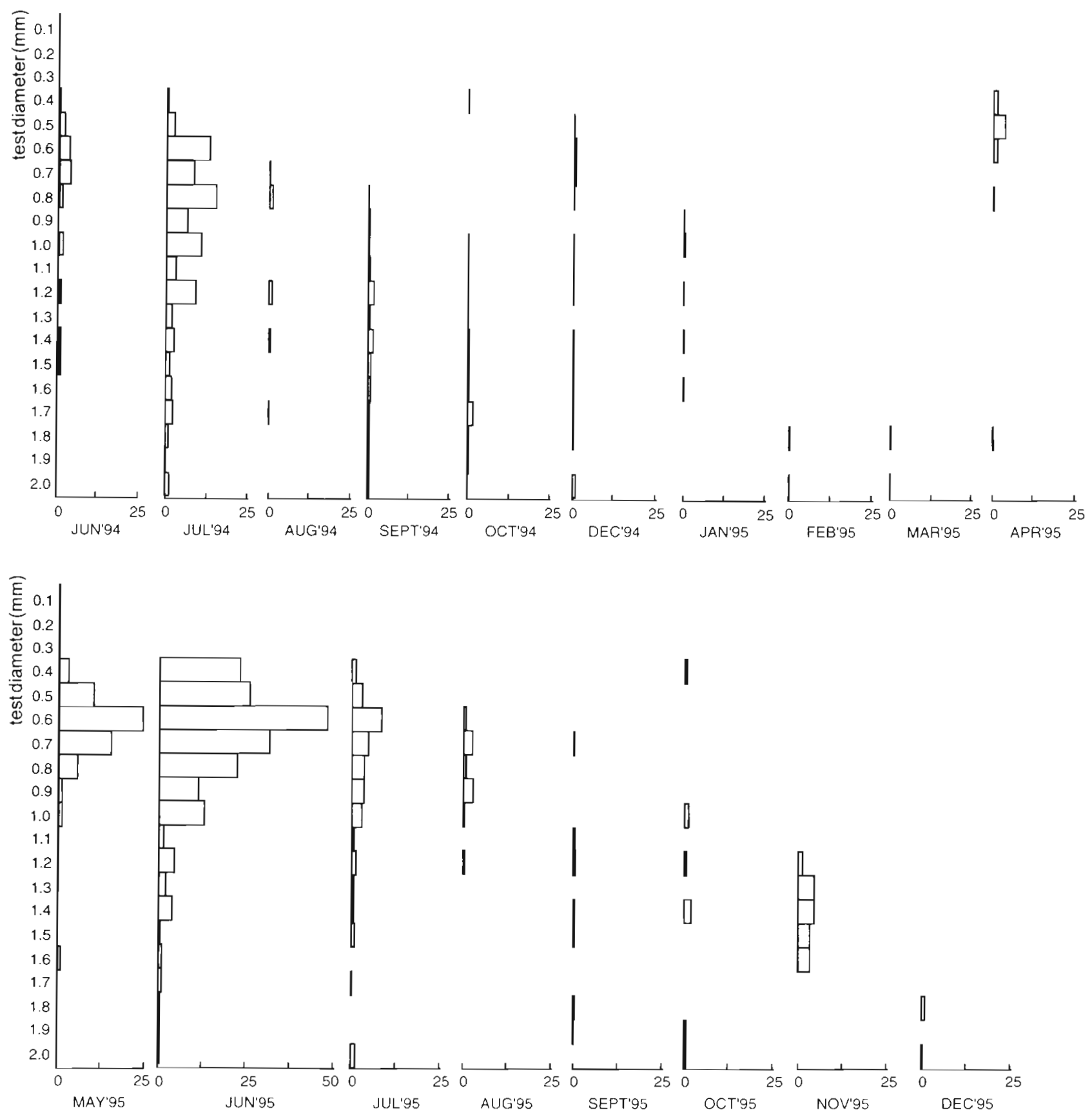

Fig. 8. Paracentrotus lividus. Test diameter distributions of the recruits during the 1994 and 1995 recruitment episodes. All samples for each month were pooled and the values of abundance refer to mean number of individuals per sample $\left(400 \mathrm{~cm}^{2}\right)$. Data are lacking for November 1994 due to bad weather conditions

cohorts and to small sample sizes (especially in winter), the 4 minima of recruit diameter observed during the 4 years occurred at the beginning of each main recruitment period, with subsequent growth of settlers afterwards (Fig. 6).

The mean number of recruits observed during the whole survey (averaging all months) increased with depth (Fig. 9), although the differences were not statis- tically significant (ANOVA, $p>0.05$ ). In contrast, the abundance of sea urchins (larger than $5 \mathrm{~mm}$ ) recorded on the same wall during 1992-93 (Turon et al. 1995a) decreased with depth (Fig. 9), and the differences among the 3 depth levels were significant (Tukey test, $p<0.01$ in all pairwise comparisons)

The early mortality of the settlers was estimated in 1992 and 1995, when recruitment was strongest. We 


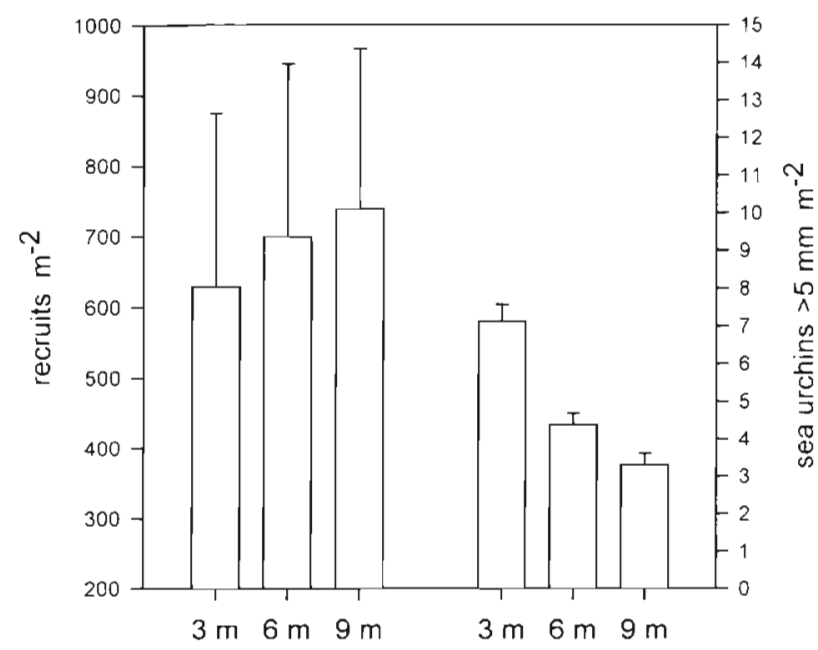

Fig. 9. Paracentrotus lividus. Total number of recruits found at the 3 depth levels and sea urchin (specimens $>5 \mathrm{~mm}$ in diameter) abundances on the same wall and depth levels. Data on sea urchin abundances from Turon et al. (1995a). Bars are standard errors

constructed size-frequency histograms with all the recruits measured during the recruitment episodes of 1992 and 1995 (Fig. 10). Pooling the samples for all the recruitment period has the advantage that these histograms represent the changes in abundance with size of all the cohorts that have arrived during this period combined, and it is more precise than trying to follow a single cohort in sequential histograms. From a size of $0.6 \mathrm{~mm}$ onwards the abundance values decreased. An exponential function $\left(N_{t}=N_{0} \mathrm{e}^{-Z \times \text { diam. }}\right)$ was fitted to the decreasing abundance, yielding an estimate of the mortality rate $(Z)$ associated with the size increments for the stage comprised between sizes of 0.6 and $2 \mathrm{~mm}$ in diameter. The $0.6 \mathrm{~mm}$ size is reasonably close to the settlement size, as the largest postlarvae found in the plankton measured over $0.4 \mathrm{~mm}$ (Grosjean et al. 1996 measured ca $0.5 \mathrm{~mm}$ for early postmetamorphs of this species). The mortality rate for the whole succession of sizes from 0.6 to $2 \mathrm{~mm}$ was 4.96 for 1992 and 5.23 for 1995 . The corresponding finite survival rates for this stage were 0.0069 in 1992 and 0.0053 in 1995. Hence, only 0.5 to $0.7 \%$ of the settlers survived until they reached a size of $2 \mathrm{~mm}$. From our histograms, we estimate that development to $2 \mathrm{~mm}$ takes 3 to $4 \mathrm{mo}$ in this population.

Further estimates of mortality were derived from the monthly size-frequency histograms corresponding to

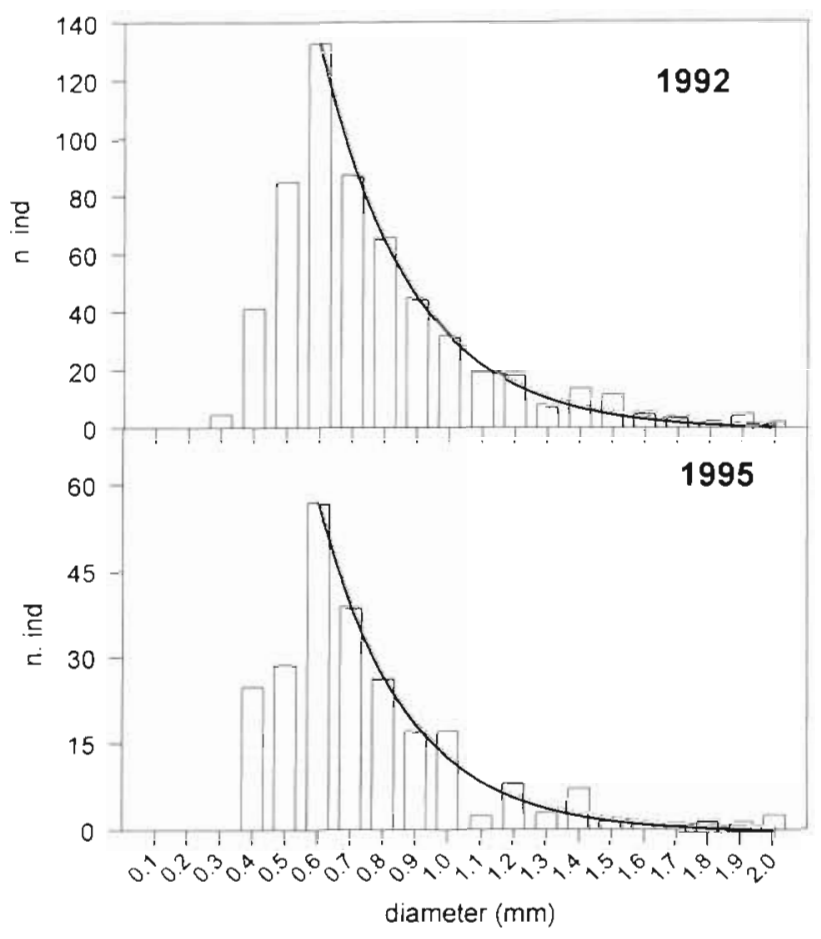

Fig. 10. Paracentrotus lividus. Abundances of recruits grouped in intervals of $0.1 \mathrm{~mm}$ in diameter, during the recruitment episodes of 1992 and 1995

a fixed vertical transect on the same wall monitored during 1993 (Turon et al. 1995a). A mode of organisms with 1 growth ring, thereby corresponding to the 1992 recruits, was clearly discernible (separation coefficient 4.42 ) for the first time in the histograms corresponding to October 1993 (Fig. 11). The Battacharya estimates gave a mean size for this cohort of $12.03 \mathrm{~mm}$ in diameter (standard deviation $=0.944$ ) and an abundance of

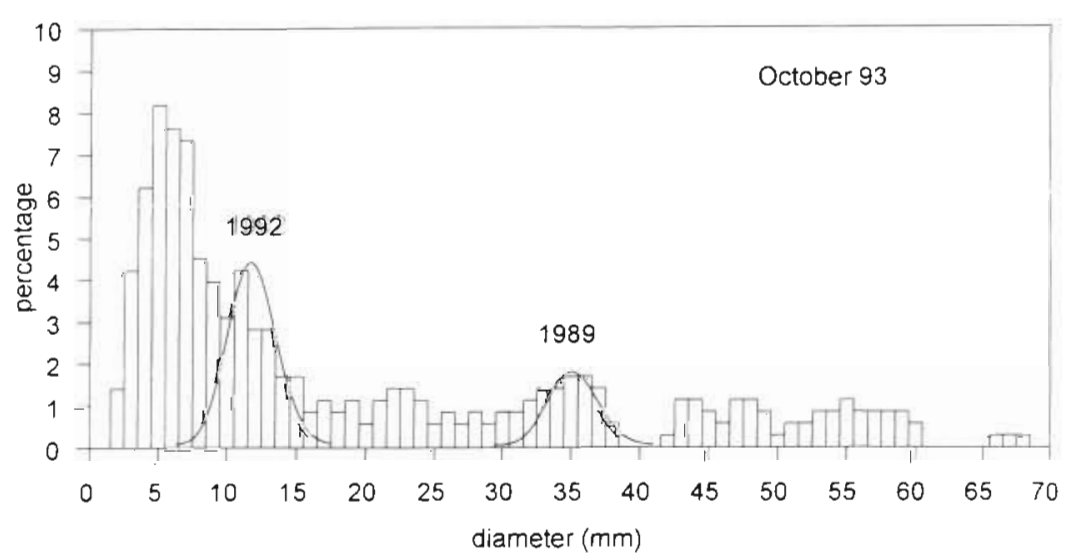

Fig. 11. Paracentrotus lividus. Size distribution (in percentages) of the sea urchin specimens along a fixed transect $(6 \times 1 \mathrm{~m})$ in October 1993. Cohorts cited in the text are indicated. Data and cohort identification obtained from Turon et al. 


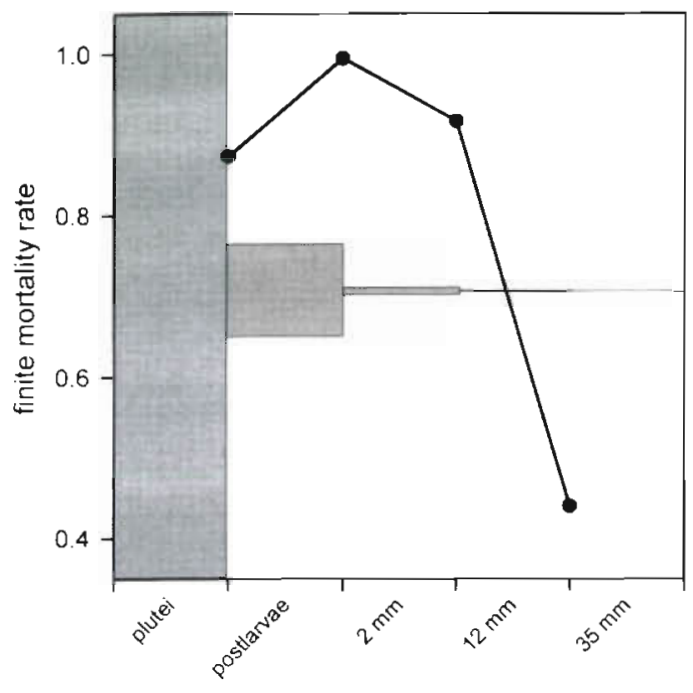

Fig. 12. Paracentrotus lividus. Finite mortality rates estimated between the diverse stages of the life history considered. The horizontally stacked bars represent the time course of a cohort of plutei: the relative thicknesses of the bars equal the proportion of survivors at each stage (assuming that all postlarvae settled successfully, and that the unknown recruitment of 1989 was as intense as that of 1992)

2.83 ind. $\mathrm{m}^{-2}$. If we compare this peak with the peak of recruits (August 1992: 7050 ind $\mathrm{m}^{-2}$ ) and assume that most of the settlement had occurred by this month (and that dispersal of newly settled juveniles is short-range, see 'Discussion'), then we conclude that the number of individuals must have been reduced by 0.9996 . This indicates that only $0.040 \%$ of settlers reached a size of about $12 \mathrm{~mm}$, corresponding to an instantaneous mortality rate of $0.019 \mathrm{~d}^{-1}$ during this period $(14 \mathrm{mo})$, which approximates the first year of benthic life.

Sexual maturity is attained by Paracentrotus lividus in Tossa at sizes of about $35 \mathrm{~mm}$ (Lozano et al. 1995). There was a distinct mode in the October 1993 sample (separation index $=5.62$ ), of individuals with 4 growth rings with a mean diameter of $35.34 \mathrm{~mm}(\mathrm{SD}=1.7)$ and an abundance of 1.98 ind. $\mathrm{m}^{-2}$, which correspond to the 1989 cohort (Fig. 11). The large interannual variability in recruitment renders the estimation of mortality from settlement to sexual maturity difficult. However, we can assume that 1989 was a year of intense recruitment, as the mode of this cohort is larger than those of the 1990 and 1991 cohorts (which, in fact, were not even clearly discernible; Fig. 11). If we take the values of 1992 as representative of a high-recruitment year and apply them to the recruitment of 1989, then only $0.028 \%$ of settlers would have survived to reach sexual maturity (instantaneous mortality rate of $0.0054 \mathrm{~d}^{-1}$ ). Of course, this estimate is only tentative, survival might have been higher if the recruitment in 1989 was less intense than in 1992 or lower if the reverse was true. The combination of the mortality estimates for the different stages (Fig. 12) indicates that the highest mortality is concentrated in the planktonic life and in the first months of benthic life.

\section{DISCUSSION}

The results presented unambiguously indicate that the recruitment of Paracentrotus lividus occurs mostly between May and August, depending on the year, although minor recruitment episodes were also apparent in autumn and winter. The present controversy about the number of recruitment episodes probably derives from the fact that these smaller recruitments may be highly variable in intensity, both geographically and temporally. Whenever they are sufficiently strong, they can lead to reports of bi- or even multimodal recruitment dynamics, while they can be easily overlooked when they are weak, resulting in an apparently unimodal pattern. The histological study of the gonads in the same zone during 1992-93 (Lozano et al. 1995) showed that, after the main gamete release, the gonads can be quickly restored to maturity, and from the end of October some mature gametes are available, thus allowing for partial releases. The statement by Lozano et al. (1995) that an autumnal spawning is not possible was a misinterpretation and needs to be revised. A recent histological study of this species in Brittany, France, has revealed a comparatively slower gametogenic pace, as gonads grew during autumn and winter and matured in spring (Spirlet et al. 1998). The main spawning period, however, occurred at about the same time in the Atlantic and the Mediterranean populations studied (spring-early summer; Lozano et al. 1995, Spirlet et al. 1998).

Most of the evidence points to a predominant role of temperature in the regulation of gametogenesis, reproduction, and larval development in sea urchins (Cochran \& Engelmann 1975, Ebert 1983, Hart \& Scheibling 1988, Fujisawa \& Shigei 1990, Spirlet et al. 1998), although photoperiod seems important for some echinoid species (Pearse et al. 1986, McClintock \& Watts 1990, but see Cochran \& Engelmann 1975). However, the actual factors triggering the spawning episodes are not known with certainty. Photoperiod (Spirlet et al. 1998), phytoplankton blooms (Himmelman 1975, Starr et al. 1990, 1993, Pedrotti 1993) or turbulence (Pedrotti 1993) have been proposed as triggers of spawning. Our results suggest that the timing of reproduction may be controlled by temperature, as the progressive advancement found at the onset of the main recruitment peak correlated with an advancement in the spring temperature rise during these years. However, the magnitude of the recruitment events was independent 
of temperature. Instead, the size of the peak larval abundance and, therefore, the recruitment to the benthos was linked to interannual differences in the magnitude of the late winter phytoplankton blooms and the associated primary production. The late winter bloom of phytoplankton, which is a recurrent feature of the NW Mediterranean littoral, has been shown to be followed by the release of larvae (Andreu \& Duarte 1996) and subsequent recruitment to the benthos (Pinedo et al. 1996) of many groups of benthic invertebrates. This phytoplankton bloom, therefore, appears to be closely coupled to the reproductive output of benthic invertebrates in the NW Mediterranean. The mechanism by which planktonic production and sea urchin larval abundances are linked, however, cannot be unambiguously established at present. Some authors (Himmelman 1975. Starr et al. 1990) have found a direct coupling of invertebrate spawning with phytoplankton blooms. Such a direct effect is not possible in our case, since there is a 2 to 3 mo lag between the late winter phytoplankton peak and the period of high larval abundance. Pulses of phytoplankton may result in pulses of microphytobenthos, resulting in an enhanced supply of carbon to the benthos (mainly in the form of diatom aggregates) during bloom periods. This may contribute to a good nutritional state of the sea urchins which can enhance reproduction. However, the time course of the gonadosomatic index in Paracentrotus lividus indicates that the main period of gonad building is before the winter (Lozano et al. 1995), so it is not clear how a late winter process can influence substantially the reproductive output in the same year. Another explanation would be that sea urchins produce offspring independently of the plankton production, but that survival of the young larvae is enhanced in the presence of abundant planktonic resources. This hypothesis requires that the size of the late winter phytoplankton bloom should also determine food availability at the time when echinoid larvae appear. This may happen through regulation of the blooms of bacteria, nanoflagellates and ciliates, which peaked in the area after the phytoplankton blooms (Andreu \& Duarte 1996, Vaqué 1996), thereby providing abundant food items to sustain the survival and growth of the larvae in spring. The size of the bloom of microheterotrophs is related to the size of the phytoplankton bloom (Duarte et al. unpubl. results), thus providing an explanation for the interannual relationship found that bridges the temporal gap between phytoplankton and $P$. lividus larvae peaks. As we found mainly 8 -armed plutei in our samples, it is likely that the size of the larval pool is established through differential mortality at earlier stages. Indeed, food limitation may be one of the main factors controlling recruitment success in invertebrates (Olson \& Olson 1989), and Fenaux et al.
(1994) have substantiated that food limitation for echinoderm larvae is possible in the northwestern Mediterranean.

Although results derived from examination of plankton and benthic samples were coherent, they differed in precision and the sampling effort required. The distribution of planktonic larvae was extremely patchy, which resulted in high intersample variability and short-term variability. The maximum in June 1992, for instance, was derived from a single sampling event (June 1). Hence, even with weekly samples, the probability of missing peaks of larval abundance is very high. The standard deviation of the number of plutei in the samples was almost twice the value of the mean in June 1992. In contrast, recruits were found in the benthic samples collected the following month (July 1992), and we obtained recruits in all samples and at all depth levels, the standard deviation of the abundance of recruits being one-half of the value of the mean. Hence, the elucidation of the recruitment dynamics from plankton samples requires a much greater sampling effort, and involves greater uncertainty, than that of benthic monitoring of recruitment. Benthic populations record the 'history' of past events, which can be traced from the analysis of size distributions that yield estimates of the settling time and mortality rates.

A main difficulty in the study of recruitment to the benthos is the need to resolve the small size $12 \mathrm{~mm}$ or less) of most benthic invertebrates at the early postsettlement stages. Studies of the recruitment of sea urchins often consider specimens much larger (usually from 5 to $15 \mathrm{~mm}$ ) than settlement sizes as recruits. Size-frequency distribution studies also neglect, in most cases, specimens $<3 \mathrm{~mm}$, as pointed out by Pearse \& Cameron (1991), and are thus unreliable for assessing settlement. The estimation of the realized settlement is a cornerstone of the assessment of the relative importance of postsettlement phenomena (Harrold et al. 1991, Ebert et al. 1994), and usually requires high-frequency sampling (about daily; Gosselin \& Qian 1997) to estimate mortality during the crucial first days or weeks. We should acknowledge that our biweekly or monthly sampling frequency resulted in some uncertainty, although measuring juveniles and constructing size-frequency distributions did compensate in some way for this lack of accuracy. For instance, the juveniles observed in April and May 1995 could be identified as new settlers $(<1 \mathrm{~mm}$ in diameter), while we could ascertain that the juveniles observed in November 1995 were not recent settlers ( $>1 \mathrm{~mm}$ in diameter), but the result of the growth of previously arrived individuals.

Another requirement for the validity of the benthic studies is that the range of movement of the juveniles should be restricted. To our knowledge, no study has 
addressed this point in sea urchins. Although the range of movement of the adults of this species is short (about $50 \mathrm{~cm}$ around the shelter; Dance 1987), several works have demonstrated considerable dispersal capabilities in juvenile invertebrates with limited dispersal as adults (Martel \& Chia 1991, Armonies 1994, 1996). However, these instances refer mostly to some bivalves and gastropods, for which mechanisms (byssus drifting, mucous thread drifting) have been described that allow the juveniles to enter the water column. In the many studies on echinoderm recruitment (reviewed in Strathmann 1978) no such mechanism has been reported for this group. Moreover, in a recent survey of the events taking place during the settlement of Paracentrotus lividus (Gosselin \& Jangoux 1998), no reference is made to any ability of metamorphic sea urchins to re-enter the water column. Of course, displacements due to water movement cannot be ruled out, but the presence of an algal canopy and the fact that juvenile sea urchins usually occupy sheltered places such as small crevices in coralline algae make us reasonably confident that the juveniles are not brought away by currents or wave action and that our present estimates are reliable.

Our results identify the larval period, and the first year of benthic existence, especially the early postsettlement period, as the key bottlenecks for the success of a cohort. Pedrotti \& Fenaux (1992) found that postlarval stages of Paracentrotus lividus accounted for $1.2 \%$ of the 4 -armed larval stages observed in the plankton of Villefranche-Sur-Mer (France), and attributed this decrease to mortality and dispersion. Natural survival rates for plutei of Strongylocentrotus spp. ranging from ca 5 to ca $35 \%$ have been reported (Rumrill 1990). Postlarvae represented about $12.7 \%$ of the pluteus stages in Blanes Bay, although we were not able to trace larval cohorts from the 4 -arm stage, so the total mortality during the planktonic life (between $20 \mathrm{~d}$ and 1 mo; Fenaux et al. 1985. Pedrotti 1993) may be well above this figure. It should be noted that our study did not allow us to separate mortality from other processes, such as dispersion of larvae or arrival of new larval stocks to the study area. Monitoring of larval cohorts in the plankton offers the most direct evidence for natural mortality but, unavoidably (except if some marker can be used), there is a lack of confidence that larvae were sampled from a continuous population (Rumrill 1990), and interpretation of the estimates requires some caution. In addition, our results indicate that mortality in the plankton is density-dependent in this species. A 100 -fold reduction in recruits during the settlement and postsettlement period appears to be common in invertebrates (Thorson 1966, Rumrill 1990). This is consistent with our finding that only 0.5 to $0.7 \%$ of settlers reached a size of $2 \mathrm{~mm}$ (in about 3 to 4 mo of benthic existence), indicating that the juvenile mortality in this species may be even higher than the mortality during the planktonic period.

Early postsettlement processes appear to be at least as important as larval processes in determining the distribution and abundance of Paracentrotus lividus adults, which may be a common pattern among invertebrates (cf. Gosselin \& Qian 1997). Mortality is still high afterwards, with ca $0.04 \%$ of settlers reaching diameters of about $12 \mathrm{~mm}$ after some $14 \mathrm{mo}$, indicating survival rates of around $10 \%$ between 2 and $12 \mathrm{~mm}$. In laboratory experiments, juvenile $P$. lividus fed ad libitum grew somewhat faster (size of $17 \mathrm{~mm}$ after $12 \mathrm{mo}$; Grosjean et al. 1996), but growth is probably slower in natural conditions. In fact, Cellario \& Fenaux (1990) found marked growth differences in this species, depending on culture conditions. Recruitment sensu Hunt \& Scheibling (1997), i.e. the addition of new individuals to the breeding population, may be achieved by only ca $0.028 \%$ of the settlers. Thus, mortality appeared to be much lower after the first year (more than $40 \%$ survival between $12 \mathrm{~mm}$ and reproductive size). The depth-dependent differences in adult abundance observed are clearly a postsettlement phenomenon, although we are unable at present to isolate differential mortality from migration as the structuring force.

In conclusion, the data obtained for Paracentrotus lividus suggest that the timing of reproduction is influenced by temperature, but that the size of the larval pool is related to planktonic primary production. There is a positive relationship between variations in phytoplankton, larval abundance and recruitment over the study period. Hence, the population dynamics of this species appears to be linked to year-to-year variations in reproductive success, which lead to strong or weak larval cohorts. Our data did not allow us to determine whether the size of the larval pool studied (composed mainly of 8-armed plutei and more advanced stages) is set by differential reproductive output or by differential mortality between the 4 - and 8 -armed pluteus stage, although we argue that the latter seems more likely. The study of interannual differences in reproductive investment and fertilisation success deserves more attention. Once this larval pool is set, the main bottlenecks for the success of any cohort appear to be the planktonic period and the first year of benthic life, particularly the early postsettlement phase.

Acknowledgements. This study was funded by projects PB950015. MAR91-0503 and AMB94-0746 of the Spanish Interministerial Commission for Science and Technology (CICYT). Funding was also provided by the Fisheries Department of the Catalan Government. We thank M. Ballesteros, S. Carner, G. Giribet, J. Lozano, J. Galera and G. Morera (Univ. of 
Barcelona) for their help with the field work. M. L. Pedrotti (Station Biologique, Villefranche-Sur-Mer, France) and P. Gosselin (Univ. de Mons-Hainaut, Belgium) helped with useful comments, and S. Agustí (CEAB, Blanes) provided unpublished data on primary production. We also thank 2 anonymous reviewers for helpful comments on the manuscript.

\section{LITERATURE CITED}

Andreu P, Duarte CM (1996) Zooplankton seasonality in Blanes Bay (northwestern Mediterranean). Publ Espec Inst Esp Oceanogr 22:47-54

Armonies W (1994) Driftung meio- and macrobenthic invertebrates on tidal. flats in Koenigshafen: a review. Helgol Meeresunters 48:299-320

Armonies W (1996) Changes in distribution patterns of 0 group bivalves in the Wadden Sea: byssus-drifting releases juveniles from the constraints of hydrography. J Sea Res 35:323-334

Azzolina JF (1988) Contribution a l'étude de la dynamique des populations de l'oursin comestible Paracentrotus lividus (Lamarck). Croissance, recrutement, mortalité, migrations. PhD thesis, Univ Aix-Marseille II

Battacharya CG (1967) A simple method of resolution of a distribution into Gaussian components. Biometrics 23: $1.15-135$

Byrne M (1990) Annual reproductive cycles of the commercial sea urchin Paracentrotus lividus from an exposed intertidal and a sheltered subtidal habitat on the west coast of Ireland. Mar Biol 104:275-289

Cameron RA, Schroeter SC (1980) Sea urchin recruitment: effect of substrate selection on juvenile distribution. Mar Ecol Prog Ser 2:243-247

Cellario C, Fenaux L (1990) Paracentrotus lividus (Lamarck) in culture (larval and benthic phases): parameters of growth observed during two years following metamorphosis. Aquaculture 84:173-188

Cochran RC. Engelmann F (1975). Environmental regulation of the annual reproductive season of Strongylocentrotus purpuratus (Stimpson). Biol Bull 148:393-401

Crapp GB, Willis ME (1975) Age determination in the sea urchin Paracentrotus lividus (Lamarck), with notes on the reproductive cycle. J Exp Mar Biol Ecol 20:157-178

Dance D (1987) Patterns of activity of the sea urchin Paracentrotus lividus in the bay of Port-Cross (Var. France, Mediterranean). PSZN I: Mar Ecol 8:131-142

Ebert TA (1983) Recruitment in Echinoderms. In: Jangoux M, Lawrence JM (eds) Echinodem studies. Vol 1. AA Balkema, Rotterdam, p 169-203

Ebert TA, Schroeter SC, Dixon JD (1994) Settlement patterns of red and purple sea urchins (Strongylocentrotus franciscanus and $S$. purpuratus) in California, USA. Mar Ecol. Prog Ser 111:41-52

Fenaux L (1968) Maturation des gonades et cycle saisonnier des larves chez $A$. lixula, $P$. lividus et $P$. microtuberculatus (échinides) à Villefranche-Sur-Mer. Vie Milieu 19:1-52

Fenaux L (1969) Les échinopluteus de la Méditerranée. Bull Inst Océanogr Monaco 68 (1394): 1-28

Fenaux L, Cellario C, Etienne M (1985) Croissance de la larve de l'oursin Paracentrotus lividus. Mar Biol 86:151-157

Fenaux L, Pedrotti ML (1988) Metamorphose des larves d'Echunides en pleine eau. PSZN I: Mar Ecol 9:93-107

Fenaux L, Strathmann M, Strathmann R (1994) Five tests of food-limited growth of larvae in coastal waters by comparisons of rates of development and form of echinoplutei. Limnol Oceanogr 39:84-98
Fujisawa $H_{1}$ Shigei $M(1990)$ Correlation of embryonic temperature sensitivity of sea urchins with spawning season. J Exp Mar Biol Ecol 136:123-139

Gosselin LA, Qian PY (1997) Juvenile mortality in benthic invertebrates. Mar Ecol Prog Ser 146:265-282

Gosselin P. Jangoux M (1998) From competent larvd to exotrophic juvenile: a morphofunctional study of the perimetamorphic period of Paracentrotus lividus (Echinodermata, Echinoida). Zoomorphology 118:31-43

Grosjean P, Spirlet C, Jangoux M (1996) Experimental study of growth in the echinoid Paracentrotus lividus (Lamarck, 1816) (Echinodermata). J Exp Mar Biol Ecol 201:173-184

Guettaf $M$ (1997) Contribution à l'étude du cycle réproductif de l'oursin Paracentrotus lividus en Méditerranée Sud Occidentale. PhD thesis, Univ Aix-Marseille II

Harrold C. Lisin S, Light KH, Tudor S (1991) Isolating settlement from recruitment of sea urchins. J Exp Mar Biol Ecol $147: 81-94$

Hart MW, Scheibling RE (1988) Heat waves, baby booms, and the destruction of kelp beds by sea urchins. Mar Biol 99 $167-176$

Himmelman JH (1975) Phytoplankton as a stimulus for spawning in three marine invertebrates. J Exp Mar Biol Ecol 20:199-214

Hunt HL, Scheibling RE (1997) Role of early postsettlement mortality in recruitment of benthic marine invertebrates Mar Ecol Prog Ser 155:269-301

Kempf M (1962) Recherches d'écologie comparée sur Paracentrotus lividus (Lmk) et Arbacia lixula (L.). Rec Trav St Mar End 25(39):47-116

Lozano J, Galera J, López S, Turon X, Palacín C, Morera G (1995) Biological cycles and recruitment of Paracentrotus lividus (Lamarck) (Echinodermata: Echinoidea) in two contrasting habitats. Mar Ecol Prog Ser 122:179-191

Martel A, Chia FS (1991) Drifting and dispersal of small bivalves and gastropods with direct development. J Exp Mar Biol Ecol 150:131-147

Martin D, Claret M, Pinedo S, Sardá R (1997) Vertical and spatial distribution of the near-shore littoral meroplankton off the Bay of Blanes (NW Mediterranean). J Plankton Res 19:2079-2089

McClintock JB, Watts SA (1990) The effects of photoperiod on gametogenesis in the tropical sea urchin Eucidaris tribuloides (Lamarck) (Echinodermata: Echinoidea). J Exp Mar Biol Ecol. 139:175-184

Mortensen T (1977) Handbook of the echinoderms of the British Isles. W Backhuis, Rotterdam

Mura MP, Agustí S, Cebrián J, Satta MP (1996) Seasonal variability of phytoplankton biomass and community composition in Blanes Bay (1992-1994). Publ Espec Inst Esp Oceanogr 22:23-29

Nédelec $H$, Verlaque M (1984) Alimentation de l'oursin Paracentrotus lividus (Lam.) dans un herbjer à Posidonia oceanica (L.) Delile en Corse (Méditerranée, France). In: Boudouresque CF, De Grissac JA, Olivier J (eds) International Workshop on Posidonia oceanica beds, Vol 1. GIS Posidonıe, Porquerolles, p 349-364

Olson RR, Olson MH (1989) Food limitation of planktotrophic marine invertebrate larvae: does it control recruitment success? Annu Rev Ecol Syst 20:225-247

Palacin C, Giribet G, Carner S, Dantart L, Turon X (1998) Low densities of sea urchins influence the structure of algal assemblages in the western Mediterranean. J Sea Res 39: $281-290$

Pauly D, David N (1981) ELEFAN I, a BASIC program for the objective extraction of growth parameters from length-frequency dala. Meeresforsch Rep Mar Res 28:205-211 
Pearse JS, Cameron RA (1991) Echinodermata: Echinoidea. In: Giese AC, Pearse JS, Pearse VB (eds) Reproduction of marine invertebrates, Vol VI, Echinoderms and Lophophorates. The Boxwood Press, Pacific Grove, $p$ $513-662$

Pearse JS, Hines AH (1987) Long-term population dynamics of sea urchins in a central California kelp-forest: rare recruitment and rapid decline. Mar Ecol Prog Ser 39: $275-283$

Pearse JS, Pearse VB, Davis K (1986) Photoperiodic regulation of gametogenesis and growth in the sea urchin Strongylocentrotus purpuratus. J Exp Zool 237:107-118

Pedrotti ML (1993) Spatial and temporal distribution and recruitment of echinoderm larvae in the Ligurian sea. J Mar Biol Assoc UK 73:513-530

Pedrotti ML, Fenaux L (1992) Dispersal of echinoderm larvae in a geographical area marked by upwelling (Ligurian Sea, NW Mediterranean). Mar Ecol Prog Ser 86:217-227

Pinedo S, Sarda R, Martín D (1996) Seasonal dynamics and structure of soft-bottom assemblages in Blanes Bay (northwestern Mediterranean). Publ Espec Inst Esp Oceanogr $22: 61-70$

Pressoir L (1959) Contribution à la connaissance des Échinoplutéus de Paracentrotus Iividus Lmck, et Psammechinus microtuberculatus Blainv. Bull lnst Océanogr Monaco 56(1142):1-22

Rumrill SS (1990) Natural mortality of marine invertebrate larvae. Ophelia 32:163-198

Sala E, Zabala M (1996) Fish predation and the structure of the sea urchin populations in the NW Mediterranean. Mar Ecol Prog Ser 140:71-81

Satta MP, Agustí S, Mura MP, Duarte CM (1996) Seasonal variability of planktonic gross primary production in Blanes Bay (March 1992-March 1994). Publ Espec Inst Esp Oceanogr 22:31-38

Editorial responsibility: Otto Kinne (Editor),

Oldendorf/Luhe, Germany
Spirlet C, Grosjean P, Jangoux M (1998) Reproductive cycle of the echinoid Paracentrotus lividus: analysis by means of the maturity index. Invert Repr Dev 34:69-81

Starr M, Himmelman H, Therriault JC (1990) Direct coupling of marine invertebrate spawning with phytoplankton blooms. Science 247:1071-1074

Starr M, Himmelman H, Therriault JC (1993) Environmental control of green sea urchin, Strongylocentrotus droebachiensis, spawning in the St. Lawrence Estuary. Can J Fish Aquat Sci 50:894-901

Strathmann RR (1978) Larval settlement in echinoderms. In: Chia FS, Rice ME (eds) Settlement and metamorphosis of marine invertebrate larvae. Elsevier, New York, p 235-246

Thorson G (1966) Some factors influencing the recruitment and establishment of marine benthic communities. Neth $\mathrm{J}$ Sea Res 3:267-293

Turon X, Giribet G, Palacín C, López S (1995a) Growth and population structure of Paracentrotus lividus (Lamarck) (Echinodermata: Echinoidea) in two contrasting habitats. Mar Ecol Prog Ser 122:193-204

Turon X, Palacín C, Ballesteros M, Dantart L (1995b) A case study of stock evaluation on littoral hard substrata: echinoid populations on the northeast coast of Spain. In: Eleftheriou A, Ansell A.D, Smith CJ (eds) The biology and ecology of shallow coastal waters. Proc 28th Eur Mar Biol Symp. Olsen and Olsen, Fredensborg, p 333-339

Vaqué D (1996) Seasonal dynamics of planktonic microbial communities on the coast of the northwestern Mediterranean sea. Publ Espec Inst Esp Oceanogr 22:3-46

Verlaque $M$ (1984) Biologie des juvéniles de l'oursin herbivore Paracentrotus lividus (Lamarck): sélectivité du broutage et impact de l'espèce sur les communautés algales de substrat rocheux en Corse (Méditerranée, Francel. Botanica Mar 27:401-424

Submitted: April 9, 1998; Accepted: July 31, 1998

Proofs received from author(s): September 25, 1998 